\title{
Shear Rehabilitation of RC Deep Beams using NSM CFRP Anchor Bars
}

\author{
Abdul Aziz Abdul Samad ${ }^{1}$, Douread R. Hassen ${ }^{1, *}$, Noridah Mohamad ${ }^{1}$, Ali Naji Attiyah ${ }^{2}$, \\ $J$. Jayaprakash ${ }^{3}$, and Priyan Mendis ${ }^{4}$ \\ ${ }^{1}$ Faculty of Civil and Environmental Engineering, Universiti Tun Hussein Onn Malaysia, 86400 Parit \\ Raja, Batu Pahat, Johor, Malaysia \\ ${ }^{2}$ Faculty of Civil Engineering, University of Kufa, Kufa, P.O. Box (21), Najaf Governorate, Iraq \\ ${ }^{3}$ Department of Civil Engineering, University of Nottingham Malaysia Campus, Jalan Broga, 43500 \\ Semenyih, Selangor, Malaysia \\ ${ }^{4}$ Department of Infrastructure Engineering, University of Melbourne, Parkville, 3010 Victoria, \\ Australia
}

\begin{abstract}
This paper presents results of an experimental study for the shear strengthening of reinforced concrete (RC) deep beam using near surface mounted (NSM) carbon fiber reinforced polymer (CFRP) anchor bars. To ensure shear failure, five RC deep beam specimens were cast with nominal shear reinforcement. Shear strengthening of the RC deep beams was conducted by inserting $5 \mathrm{~mm}$ diameter by $450 \mathrm{~mm}$ length of CFRP bars as anchors with spacing of $100 \mathrm{~mm}$ and $150 \mathrm{~mm}$ centre to centre from the support of the beam. All RC beams were simply supported and subjected to a four-point bending test with shear span to effective depth ratio of 0.864 . The results presented include the ultimate load, CFRP contribution to shear, modes of failure and the load-deflection profile. The shear enhancement of the RC deep beams shows an increment of $17.3 \%$ up to $25.5 \%$ with decreasing mid-span deflection from $6.4 \%$ to $15.1 \%$. In addition, using this technique also increases its flexural beam resistance under the same conditions.
\end{abstract}

\section{Introduction}

Near surface mounted (NSM) is one of the most favorable and up-to-date technique for strengthening and repairing damage reinforced concrete structures. Normally NSM technique involves cutting groove along the concrete surface or concrete cover of the structural member and followed by embedding carbon fiber reinforced polymer (CFRP) bars into these grooves. These CFRP bars are than bonded to the concrete grooves by using epoxy resin.

Literature has shown that the NSM technique has been introduced in Europe since the 1950 's. In fact, since the last decade, numerous research on NSM has been conducted by various researchers focusing on strengthening of damage structures in flexure using either CFRP laminates, strips or rods [1-6].

\footnotetext{
* Corresponding author: dou_444@yahoo.com
} 
However, the authors observed that research on using NSM for shear strengthening for reinforced concrete (RC) deep beams have not been thoroughly investigated [7]. Hence, a new approach to using the NSM CFRP techniques for the strengthening of RC deep beams in shear is presented.

Two NSM techniques were applied concurrently for the strengthening of the RC deep beams. Firstly, within the shear span of the beam, CFRP bars of $5 \mathrm{~mm}$ diameter by $450 \mathrm{~mm}$ length were inserted vertically (from the bottom upwards) inside the RC deep beam as anchors. The CFRP anchor bars are located adjacent and on each side of the existing steel reinforcement of the RC deep beams. Secondly, additional CFRP longitudinal bars were located in grooves along the soffit of the beam. Five RC deep beams (one control beam and four beams strengthened by the NSM technique) were cast and tested until failure. In this research, the test variables were the spacing of the CFRP anchor bars from the support of the beam. The ultimate load, CFRP contribution to shear, modes of failure and loaddeflection profile of the NSM strengthened RC deep beams are presented and discussed in this paper. Subsequently, the experimental results from the NSM strengthened RC deep beams are compared with the control beam.

\section{Experimental program}

This paper studies the structural performance of applying near surface mounted (NSM) CFRP anchor bars in shear and additional CFRP longitudinal bars in flexure to strengthened RC deep beams with shear discrepancies. Control deep beam (C1) was reinforced in flexure with three $16 \mathrm{~mm}$ diameter steel bars at the bottom, two $12 \mathrm{~mm}$ diameter steel bars at the top. To ensure that the RC deep beams failed in shear, nominal stirrups of $12 \mathrm{~mm}$ diameter at $200 \mathrm{~mm}$ centre to centre (c/c) was placed from the support of the beam, as specified by [8]. R1, R2, R3 and R4 are RC deep beam test specimens requiring strengthening using CFRP anchor and longitudinal bars. All four beams were similarly reinforced in shear and flexure as control beam $\mathrm{C} 1$. However, for beam specimens $\mathrm{R} 1$ and R2, shear strengthening was done by inserting $6 \mathrm{~mm}$ diameter CFRP anchor bars with spacing of $100 \mathrm{~mm} \mathrm{c} / \mathrm{c}$ from the support. Two numbers of $6 \mathrm{~mm}$ diameter NSM CFRP longitudinal bars was placed along a groove located at the soffit of the beam. Similar CFRP bar arrangements were applied to beam specimens R3 and R4 but with CFRP anchor bar spacing at $150 \mathrm{~mm} \mathrm{c} / \mathrm{c}$. Bonding between CFRP anchor bars and longitudinal bars to the concrete deep beams was achieved by using epoxy resin. Fig. 1 shows detailed description of control beam $\mathrm{C} 1$, beam specimens R1 and R2 with CFRP anchor bars at $100 \mathrm{~mm} \mathrm{c} / \mathrm{c}$ and beam specimens R3 and R4 with CFRP anchor bars at $150 \mathrm{~mm} \mathrm{c} / \mathrm{c}$.

\subsection{Material properties}

A ready-mix concrete with target compressive strength of $30 \mathrm{MPa}$ was used. The design slump for the ready-mix concrete was targeted at $75 \mathrm{~mm}$ and the maximum aggregate size was selected at $19 \mathrm{~mm}$. Concrete compressive strength was measured from testing six numbers of $150 \mathrm{~mm}$ cubes and six numbers of $100 \mathrm{~mm}$ by $200 \mathrm{~mm}$ cylinders, as specified by [9]. Table 1 shows the average concrete compressive strength which shows good accuracy when average cube strength fcu measures at $30.5 \mathrm{MPa}$ whilst the cylindrical strength achieved $84 \%$ of its cube strength at $25.8 \mathrm{MPa}$. 


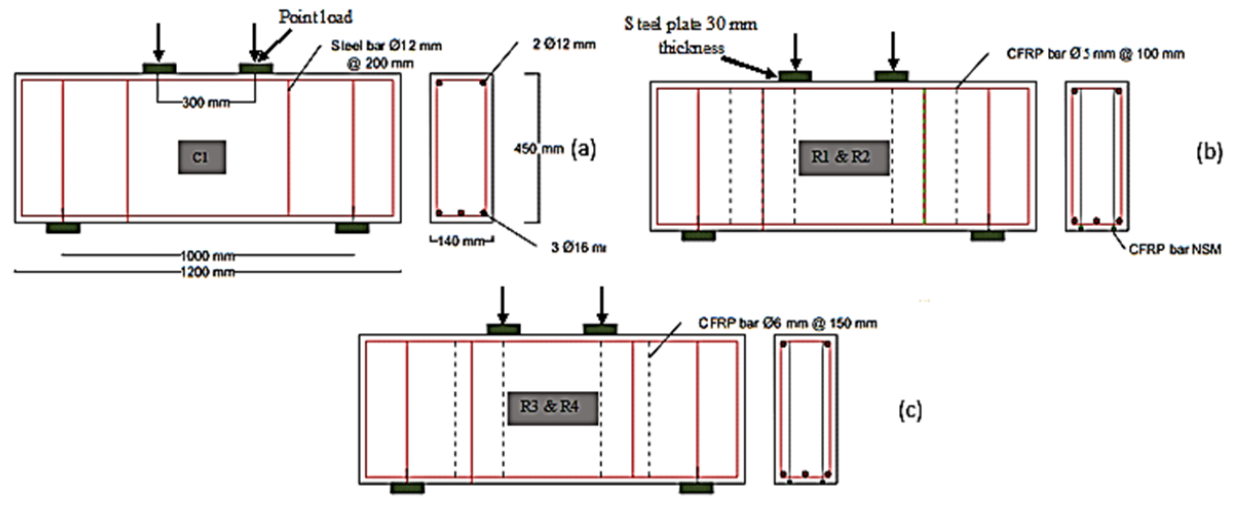

Fig. 1. (a) Control beam C1 (b) Beam specimens R1 and R2 with CFRP anchor bars at $100 \mathrm{~mm} \mathrm{c/c} \mathrm{(c)}$ Beam specimens R3 and R4 with CFRP anchor bars at $150 \mathrm{~mm} \mathrm{c} / \mathrm{c}$.

Table 1. Concrete compression strength at 28 days.

\begin{tabular}{|c|c|c|}
\hline Cubes and Cylinders & Cylinder & Cube \\
\hline Average Compressive Strength (MPa) & 25.8 & 30.5 \\
\hline
\end{tabular}

The strengthening NSM technique uses $5 \mathrm{~mm}$ diameter deformed CFRP bars and the CFRP bar properties are shown in Table 2. The stress-strain relationship for the CFRP bars was obtained by testing the CFRP bars under tension which shows a linear behaviour until a sudden rupture occurred at failure. From the stress-strain curve, a modulus of elasticity at $115 \mathrm{GPa}$ and an ultimate strength of $2300 \mathrm{MPa}$ was recorded. The CFRP strain at rupture was measured at $0.02 \%$. A typical stress-strain curve of the CFRP bars is shown in Fig. 2.

Table 2. CFRP bar properties.

\begin{tabular}{|c|c|c|c|c|}
\hline $\begin{array}{c}\text { Bar diameter } \\
(\mathbf{m m})\end{array}$ & $\begin{array}{c}\text { Cross sectional } \\
\text { area }\left(\mathbf{m m}^{\mathbf{2}}\right)\end{array}$ & $\begin{array}{c}\text { Tensile Strength } \\
(\mathbf{M P a})\end{array}$ & $\begin{array}{c}\text { Tensile Modulus } \\
(\mathbf{G P a})\end{array}$ & $\begin{array}{c}\text { Ultimate } \\
\text { Strain }(\%)\end{array}$ \\
\hline 5 & 19.63 & 2300 & 115 & 0.02 \\
\hline
\end{tabular}

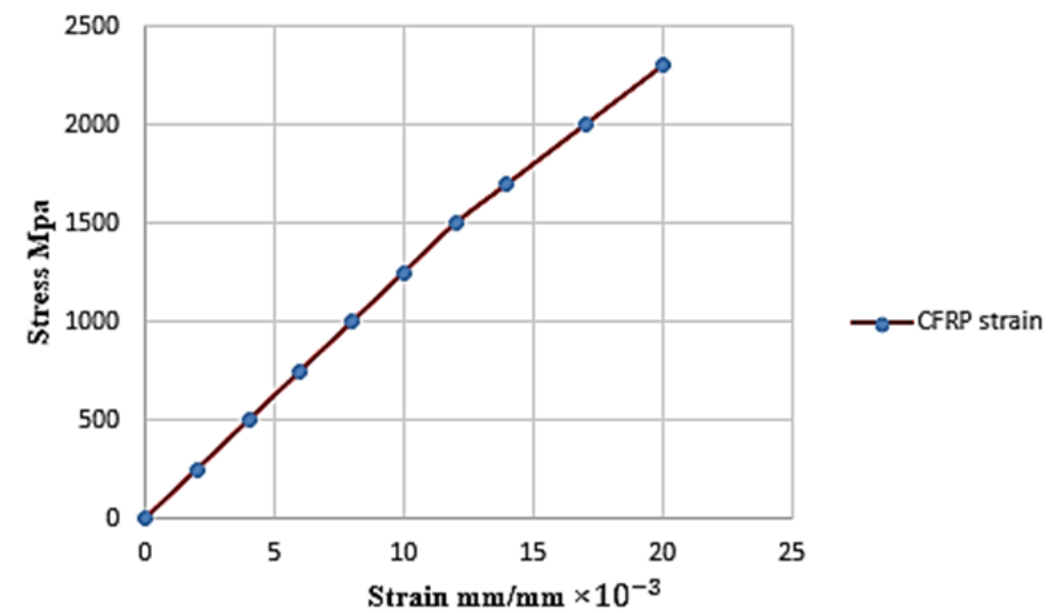

Fig. 2. Stress-strain diagram for CFRP bar. 


\subsection{Specimen preparation for NSM CFRP anchor bars and longitudinal bars}

Preparation of the four strengthened RC deep beams involved: cutting of grooves at approximately $20 \mathrm{~mm}$ square cross-section on the flexural zone (soffit) of the RC deep beams, see Fig. 3(a). This was then followed by drilling circular section along the depth of the deep beam (15 mm diameter and up to $450 \mathrm{~mm}$ in depth), see Fig. 3(b). The grooves and drilling were cleaned with water jet and air blasted to remove the powdered concrete produced by the cutting process and all the possible loose material. The epoxy paste was prepared by mixing the resin and hardener at 3:1 proportion by volume with a power mixer. The drilled area were then filled with the epoxy paste followed by the insertion of the CFRP bars through the hole. Similar to the procedure used by [2], the epoxy resin was placed to half depth of the grooves. The CFRP bars were then placed in the groove and was lightly pressed. Upon pressing, this forces the paste to flow around the bar and fill completely between the bar and the sides of the groove. The groove was filled with more paste and the surface was leveled. The specimens remained in the laboratory environment for 28 days before testing commences.

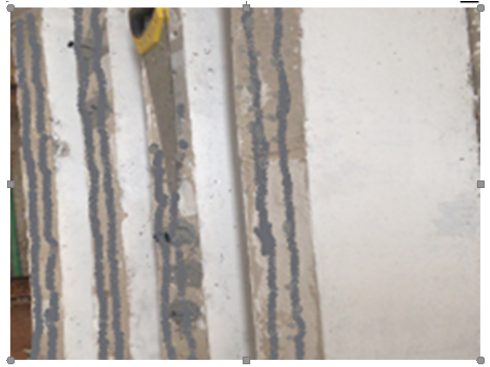

(a)

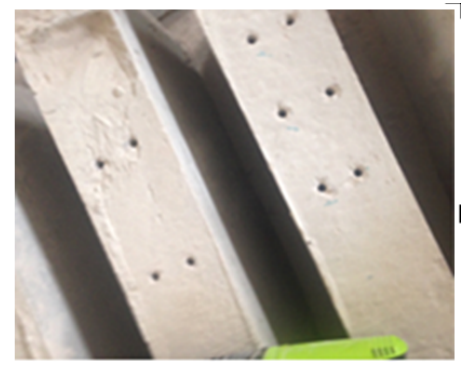

(b)

Fig. 3. (a) Installation of CFRP bars at soffit of beam with epoxy resin (b) Procedure to instill CFRP anchor bars.

\subsection{Test setup and test procedure}

Beam specimens C1, R1, R2, R3 and R4 were initially tested at 7-days on a four-point bending test as shown in Fig. 1. Load was applied incrementally until first shear crack appeared. At this point, the beams were unloaded and the shear strengthening using NSM CFRP anchor bars within the shear span was conducted. Two longitudinal CFRP bars in flexure was also added to beams R1, R2, R3 and R4. The strengthened RC deep beams were then cured and re-loaded after 28 days until failure. While specimens were reloaded, the vertical deflections at mid-span of the strengthened RC deep beams were measured using digital dial gauges, crack patterns and mode of failure were also recorded.

\section{Ultimate and mode of failure}

The shear span to effective depth ratio for all RC deep beams was measured at 0.864 . Hence, all beams failed consistently under the shear-compression mode of failure as shown in Fig. 4. Table 3 shows the experimental results for all beam specimens at failure. Control beam (C1) failed at an ultimate load of $510 \mathrm{kN}$ and shear failure at $255 \mathrm{kN}$. For all strengthened RC deep beams, R1 achieved the highest ultimate load and shear load of 641 $\mathrm{kN}$ and $320 \mathrm{kN}$. Beam R2 recorded similar ultimate and shear load at $636 \mathrm{kN}$ and $318 \mathrm{kN}$ respectively. However, when the spacing of CFRP anchor bars increases from $100 \mathrm{~mm} \mathrm{c} / \mathrm{c}$ to $150 \mathrm{~mm} \mathrm{c} / \mathrm{c}$, beam R3 and R4 shows lower ultimate and shear load. This shows that the 
spacing of the anchor bars has significant influence towards the capacity of the strengthened beams. The presence of the CFRP anchor bars has also contributed to the shear strength of the beams. This is clearly seen when the shear enhancement of $17.3 \%$ to $25.5 \%$ was recorded for all strengthened RC deep beams.
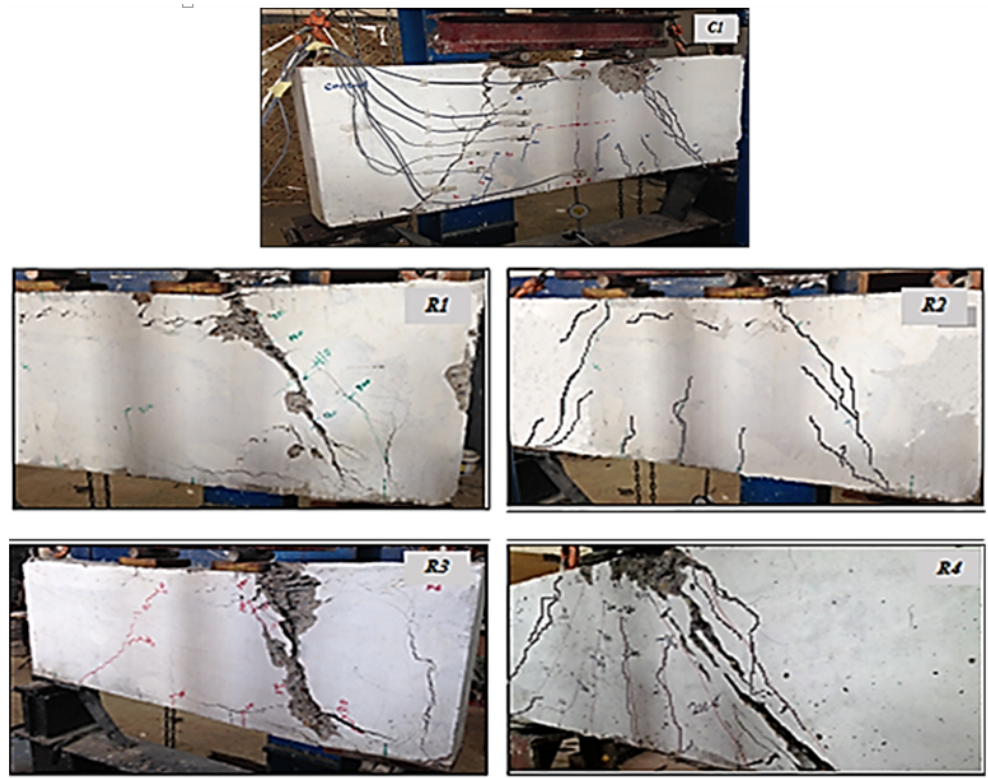

Fig. 4. Failure mode for Beam Specimens C1, R1, R2, R3 and R4.

Table 3. Experimental Results.

\begin{tabular}{|c|c|c|c|c|c|c|}
\hline & \multirow{2}{*}{ CFRP } & \multicolumn{5}{|c|}{ Experimental Results } \\
\cline { 3 - 7 } & $\begin{array}{c}\text { Condition } \\
\text { from } \\
\text { Support }\end{array}$ & $\begin{array}{c}\text { Ultimate } \\
\text { Load } \\
\text { (kN) }\end{array}$ & $\begin{array}{c}\text { Shear } \\
\text { Force } \\
\text { (kN) }\end{array}$ & $\begin{array}{c}\text { CFRP } \\
\text { Contribu- } \\
\text { tion to } \\
\text { Shear } \\
\text { (kN) }\end{array}$ & $\begin{array}{c}\text { Shear } \\
\text { Enhancement } \\
\mathbf{( \% )}\end{array}$ & $\begin{array}{c}\text { Modes of } \\
\text { Failure }\end{array}$ \\
\hline $\mathrm{C} 1$ & - & 510 & 255 & - & - & $\begin{array}{c}\text { Shear - } \\
\text { compression }\end{array}$ \\
\hline $\mathrm{R} 1$ & $100 \mathrm{~mm}$ & 641 & 320 & 65 & $25.5 \%$ & $\begin{array}{c}\text { Shear - } \\
\text { compression }\end{array}$ \\
\hline $\mathrm{R} 2$ & $100 \mathrm{~mm}$ & 636 & 318 & 63 & $24.7 \%$ & $\begin{array}{c}\text { Shear- } \\
\text { compression }\end{array}$ \\
\hline $\mathrm{R} 3$ & $150 \mathrm{~mm}$ & 604 & 307 & 52 & $20.4 \%$ & $\begin{array}{c}\text { Shear- } \\
\text { compression }\end{array}$ \\
\hline $\mathrm{R} 4$ & $150 \mathrm{~mm}$ & 598 & 299 & 44 & $17.3 \%$ & $\begin{array}{c}\text { Shear - } \\
\text { compression }\end{array}$ \\
\hline
\end{tabular}

\section{Mid-span deflection for beam specimens}

Table 4 presents the mid-span deflection and its percentage differences at failure. The midspan deflection for control beam $\mathrm{Cl}$ was recorded at $9.8 \mathrm{~mm}$. However, for the strengthened RC deep beams a reduction in deflection was observed at $8.2 \mathrm{~mm}$ for beam 
$\mathrm{R} 1$ and R2, and $9.19 \mathrm{~mm}$ and $8.93 \mathrm{~mm}$ for beams R3 and R4 respectively. This is a reduction at approximately $6.1 \%$ up to $16.3 \%$. The reduction in deflection for the strengthened RC deep beams by NSM CFRP anchor bars and longitudinal bars clearly shows an increment in its inertia value causing the RC deep beams to increase its stiffness behaviour.

Table 4. Mid-span deflection and percentage differences for beam specimens.

\begin{tabular}{|c|c|c|c|c|}
\hline Specimens & $\begin{array}{c}\text { Shear } \\
\text { Force } \\
\mathbf{( k N )}\end{array}$ & $\begin{array}{c}\text { Maximum } \\
\text { deflection } \\
\mathbf{( m m})\end{array}$ & $\begin{array}{c}\text { Difference } \\
\text { in } \\
\text { Deflection } \\
(\mathbf{m m})\end{array}$ & $\begin{array}{c}\text { Difference } \\
\text { in } \\
\text { Deflection } \\
\mathbf{( \% )}\end{array}$ \\
\hline C1 & 255 & 9.8 & - & - \\
\hline R1 & 320 & 8.2 & 1.6 & 16.3 \\
\hline R2 & 318 & 8.2 & 1.6 & 16.3 \\
\hline R3 & 307 & 9.2 & 0.6 & 6.1 \\
\hline R4 & 299 & 8.9 & 0.9 & 9.1 \\
\hline
\end{tabular}

\section{Conclusion}

This paper presents the research findings of near surface mounted (NSM) CFRP anchor bars in shear and additional CFRP longitudinal bars in flexure for the strengthening of RC deep beams with shear discrepancies. Five RC deep beams (one control beam and four strengthened beams) were tested under a four-point bending test until failure. From the results obtained, the following observation were concluded:

i) All strengthened $\mathrm{RC}$ deep beams shows higher ultimate load capacity ranging from 598 $\mathrm{kN}$ to $641 \mathrm{kN}$ compared to control beam at $551 \mathrm{kN}$.

ii) All strengthened $\mathrm{RC}$ deep beams shows an enhancement in its shear capacity with an increment of $17.3 \%$ to $25.5 \%$.

iii) A lower mid-span deflection measurements were recorded at failure indicating a stiffer response of the strengthened RC deep beams. A deflection reduction by up to $6.1 \%$ to $16.3 \%$ were achieved compared to the control beam.

iv) The strengthened RC deep beams with NSM CFRP anchor bars with additional longitudinal bars has shown good structural performance. Thus, the NSM technique has good potential for the rehabilitation work for damage RC structures in shear.

The authors would like to acknowledge the support received from Jamilus Research Centre, Faculty of Civil and Environmental Engineering and Centre for Graduate Studies of Universiti Tun Hussein Onn Malaysia.

\section{References}

[1] L.D. Lorenzis, A. Nanni and A.L. Tegola, Strengthening of reinforced concrete structures with near surface mounted FRP rods, Proc. of the Int. Advancing with Composites, 9-11, (2000)

[2] L.D. Lorenzis and A. Nanni, Shear strengthening of reinforced concrete beams with nea-surface mounted fiber-reinforced polymer rods, Int. J. ACI Structural Journal, 98(1), $60-68$ (2001)

[3] R. Parretti and A. Nanni, Strengthening of RC members using near-surface mounted FRP composites, Int. J. Advances in Structural Engineering, 7(6), 469-483 (2004) 
[4] J.A. Barros and S.J. Dias, Near surface mounted CFRP laminates for shear strengthening of concrete beams, Int. J. Cement and Concrete Composites, 28(3), 276292, (2006)

[5] J.G. Teng, L.D. Lorenzis, B. Wang, R. Li, T. N. Wong and L. Lam, Debonding failures of RC beams strengthened with near surface mounted CFRP strips, Int. J. of Composites for Construction, 10(2), 92-105, (2006)

[6] L.D. Lorenzis and J.G. Teng, Near-surface mounted FRP reinforcement: An emerging technique for strengthening structures, Int. J. of Composites Part B: Engineering, 38(2), 119-143, (2007)

[7] A.K.M.A. Islam, Contribution of NSM CFRP bars in shear strengthening of concrete members, Engineering Structures, 31(3), 709-714, (2009)

[8] ACI Committee 318-05, Building Code Requirements for Structural Concrete and Commentary, American Concrete Institute, Michigan, USA, (2005)

[9] ASTM C39-01, Standard Test Method for Compressive Strength of Cylindrical Concrete Specimens, American Society for Testing and Materials, Pennsylvania, USA, (2001) 